have kept up the inflammation; it could not/he said he was not quite so well, but but by possibility have done good. The first taken a fresh cold. He had no fever; but prescription is generally a mild tonic medi- as his breath was not quite so well, 1 told cine, not a stimulant. Quinine is a tonic. him $I$ would make an alteration in his me Infusion of roses might have been adminis- dicine by adding ether. He again said he tered if any tendency to hæmorrhage existed. Was in no pain from his bowels. I ordered The sulphuric acid, also a tonic, I consider a repetition of the pills. On the following would be injurious in such a case as this. morning his health was relieved, and still The prescription is not such a one as I should improving. He did not feel very weak, and have given; I should have considered it in- had a pretty good appetite. I expected him jurious in a case of acute inflammation. There to be weaker than I found him, owing to is nothing injurious in the second prescrip- the expectoration. I again advised him to tion; it is an innocent one, but not one cal- have further advice. In doing so I was culated to reduce inflammation. I should guided not so much by how he felt, as by have used, perhaps, more active medicines. what I considered would be the effect of the Knowing what I do now, with a man of such complaint continuing so long. I mentioned a strong constitution, I should have resorted to blistering, bleeding, \&c., and a tonic medicine would be the last I should have used. In explanation of the patient's feeling so much easier for the last two days, I consider it arose from the part of the lungs most affected being so much disorganised as to be beyond feeling. The first tonic medicine may have created such an excitement as to cause expectoration, and make the patient feel easier, while the original mischief was increased by it. The inflammation of the upper lobe was of long standing, that in the lower was more recent; very likely the gentleman attending deceased having administered the same remedy with success for the old cough, had done the same in the present instance, without looking below the surface of the com plaint, and without considering there was a fresh complaint. I should have administered tonic medicines for an old complaint, but not for a recent inflammation. The six ounces of serous effusion in the pericardium were not sufficient to cause death. In answer to the inquiry if there was anything in the state of the lungs calculated to produce sudden death, the witness explained, that from the lungs not properly performing their functions, the dark blood was on the wrong side of the heart. The heart appeared naturally large, and not so by disease. The suddenness of the death was clearly a result of the disease of the lungs.

Mr. C. Roberts being sworn, said, I am a chemist and druggist. I was in Mr. Phillips's shop on Saturday, the 27 th of November. Saw his wife, who said her husband was very unwell, and asked me to see him. I did so, and found him labouring under a bad cold, and severe pain in his head. I ordered him two aperient pills and a draught of the same description; also a diuretic mixture, to be taken every three or four hours. Next morning he said he was much relieved, but still complained of his head. I ordered him six leeches. On Monday morning I found him better in every respect, and the expectoration free. I pressed his chest and sides, and he said he was free from pain. Told him to continue the mixture. On the Wednesday morning I believe Drs. Boisragon and Cannon; he objected, told his wife if he got worse they had better send for some one. I saw him again pre. vious to the Tuesday, on the morning of the day he died; they had just finished dressing him. I found a change for the worse, but considered it was produced by the exertion of getting up. I then recommended a dose of the strengthening medicine sent the day before. Up to that time he had taken no tonic whatever; I put the medicine together myself ; it is the same as this prescription, the first, with the exception of having half $\mathbf{a}$ drachm less of the sulphuric acid. I treated the case entirely as one of cold, and not of inflammation. I did not consider any infammation existed; neither his pulse nor his complaints to me indicated the existence of such. Did not consider there was chronic inflammation. Had I supposed there was acnte inflammation, I should have pursued a different course of treatment, leeching, cupping, and bleeding. The tonic in that case would have been injurious. On calling in the evening, I found two more doses of the tonic had been given. In the course of the day he died. The expectoration was mucus and not pus.

After a few remarks from the coroner, the jury, after half an hour's consultation, brought in the following verdict: - "That James Phillips died of acute inflammation of the lungs; that he was attended during his illness by Mr. Charles Roberts, chemist and druggist, of whom he had certain medicines; but whether the medicines and medical treatment he received at the hands of the said Charles Roberts accelerated death, this jury are not in a situation positively and on their oaths to declare."

\title{
NON-MEDICAL CORONERS.
} PRESCRIBING CHEMISTS.

\section{To the Editor of THE LANCET.}

SIR,-Having observed, with satisfaction, the columns of your valuable Journal so fully occupied in advocating the rights of the medical profession, and in no less worthy a 


\begin{abstract}
Donther the cause of suffering humanity, by Te suppression of quacks and illegal prelenders, I am induced to bring to your notice, and that of the public in particular, The proceedings of a coroner's inquest (extracted from the Dorset County Chronicle of the 11th inst.), held on Monday, Nov. 1, at the Rose and Crown public-house, in the parish of Huish (Langport), Somerset, before R. T. Gaines, on the body of Mary Irans, an infant of twelve days old, that had died the previous Sunday morning, as another instance of the lamentable consequences that so frequently ensue, from the meddling interference of illiterate and.presuming chemists in the practice of our profession, and the daring and too often fatal attempts they make to alleviate the suffering of a large portion of the ignorant and unwary public.

I leave it for yourself to say, Mr. Editor, how far justice has been done to the individual (who has deprived a mother of a fond offspring, and her Majesty of a hopeful subject,) by the verdict the jury on the inquest thought proper to return.
\end{abstract}

Coroner's Inquest._-“ Caution to Mothers and Nurses.-Sarah Jeffreys, a woman living under the same roof, on being sworn, gave evidence that she was present at the birth of the child, which was a very fine one, and was healthy until the previous Thursday: the child had then become ill from some affection of the mother, but she did not think it alarmingly so; saw the child early on Saturday morning, when the mother said it was disordered in its bowels; did not know the mother intended getting medicine for it, but saw it again the same day at three o'clock, and found it convulsed from something that had been given it; heard the mother say 'Roger (meaning the chemist) has killed my child.' The mother poured ont some stuff from a bottle on the hob; witness put her finger in it and tasted it, thought it tasted like syrup of rhubarb, but would not say.

"Elizabeth Sanford, the nurse, sworn: Confirmed the evidence of Sarah Jeffreys, that the child was healthy until Thursday previous to its death; did not refuse food on Friday, though cross; at dusk on Friday evening the mother proposed that she should get something for the child; sent, in consequence, to Mr. Bernard, druggist, at Langport, for a pennyworth of syrup of rhubarb; saw him put something liquid into the phial she carried with her, and then turned round and put something from another bottle; asked him what it was he put in last, he said it was ' laudamy,' or some such name, a name she had never before heard. Witness asked him why he put it in, when she had asked only for syrup of rhubarb; he said he had added it to ease the child's bowels; witness had previously told him the bowels were disordered; gave half a teaspoonful of this mixtare at ten o'clock on Saturday; child swal- lowed some, perhaps more than half; ten minutes after taking the stuff the child seemed sleepy; left it in the cradle, as asleep, till two o'clock, when she took it out, and found it quite stiff, and ' drawn all forms.'

"Rev. C. T. Henslowe, vicar, sworn: Had seen the mother and nurse frequently; saw a bottle of Godfrey's cordial in the house two or three days after the child's birth; admonished them not to give any medicine to the child without medical advice; being from home did not see the child for some days, previous to the day before its death, when he went into the cottage, and found it lying on the knees of the mother, who said that it had been poorly, but that nothing particular was the matter; nurse assented to this; at two o'clock was called in great haste to see the infant, found it in such a state that he exclaimed that they had poisoned the child; saw some liquid on the hob, tasted it, thought it must be laudanum.

"John Prankerd, surgeon, sworn: Was sent for on Saturday before the child died; said the child would die as soon as I saw it; was comatose, and suffering under the effects of a narcotic; eyes were fixed and glassy, and the pupils very contracted; was cold in the limbs, and did not breathe except by convulsive gasps; applied mustard pultices to the feet ; opened a vein in the neck, but only a few drops of blood flowed out; sent some medicine, but was not sent for a second time; was of opinion that the child died of a narcotic poison; half a teaspoonful of syrup of rhubarb could not have caused death.

"The Autopsy-External appearances: excessive lividity of the whole surface of the body, with a small congested spot on the right side of nose; great congestion of tongue and palate, with a little frothy mucus exuding from the mouth.

"On opening the chest the lungs were found healthy; a yellow serum in the pericardium, about the usual quantity; great congestion of the vessels of the heart externally ; right auricle gorged with dark coagulated blood; right ventricle containing a similar fluid; in the left auricle and ventricle a small quantity of black blood.

"In the abdomen the stomach was found exceedingly congested, on its villous coat a deep vermilion hue, it contained a small quantity of matter of the consistence of pus, toward the pyloric orifice it was of a yellowish hue; liver healthy; right kidney congested, its pelvis filled with urine; left kidney more congested, scarcely any fluid; intestines inflated, of a reddish hue; bladder empty.

" On opening the head, the vessels on the surface of the brain were gorged with dark blood, the substance of the brain with many congested spots; the ventricles contained a small quantity of fluid." 
Remarks.-From these appearances we are of opinion that the immediate cause of death was congestion of blood in the vessels of the brain, which might, we believe, be produced by the administration of a narcotic.
(Signed)
J. Prankerd.
- Harman.

Verified on oath by

J. Prankerd, Surgeon.

The jury brought in a verdict-" Died by the visitation of God."

I need not occupy your time further, $\mathrm{Mr}$. Editor (which I fear I have too much trespassed on), than by expressing a hope that you will lay the above before your numerous readers; and trusting that it may have some effect in rousing those in authority to a right sense of their duty, and prove the necessity there exists for some remedy to put a stop to such daily and fatal occurrences, I remain, Sir, your obedient servant,

Bath, Nov. 15, 1841.

A Subscriber.

\section{MEMBERS OF THE COLLEGES OF SURGEONS.}

\section{To the Editor of The LanceT.}

SIr,-In an advertisement from the College of Surgeons, preliminary to the publication of their list of members, which appeared in October last, the members of the Edinburgh and Dublin Colleges of Surgeons practising in England or Wales, were requested to forward the same particulars of their names and qualifications as were required from the members of the college in London. In a preface to the list, it is stated that its object is to furnish certain functionaries, and the public in general, with " a correct list of qualified surgeons.”

At page 311 of the publication, two clauses are cited, from the Acts of Parliament, 4 Geo. IV. cap. 64, and 6 Geo. IV. cap. 50, in both of which, although relating solely to England and Wales, the members of the three British Colleges of Surgeons are placed on exactly the same fuoting with regard to rights and immunities.

But at no page whatever is there to be found the slightest allusion to the individual members of the Edinburgh and Dublin Colleges, who, like myself, have furnished $\mathrm{Mr}$. Secretary Belfour with their names and qualifications.

Is this onission the result of accident or inadvertence? Or, if intentional, is it just towards the Edinburgh and Dublin Colleges, towards their members in Fngland and Wales, or even towards the public? I venture to say it is not.-Remaining, Sir, your very obedient servant,

December 14, 1811.

\section{THE BRODIE MEDAL.}

\section{To the Editor of The Lancet.}

SIR,-In reply to some observations in your Notices to Correspondents regarding the Brodie medal, you have been misled by the omission in the secretary's circular of a plain statement of the facts. A guinea subscription was obtained from about four hun. dred pupils and medical men, to be appropriated to a piece of plate, or a picture, or a medal. The latter was chosen; but it was to be one consisting of a medallion of Brodie on the obverse, and a simple inscription on the reverse. The funds would then have allowed that a gold copy should be presented to Brodie himself, and a bronze copy to each of the subscribers, of the value of ten shillings. This, of course, would be reducing. the subscription to eleven shillings instead of a guinea. The committee afterwards were of opinion that the medal would be much more complete as a work of art, by baving a classical design on the reverse, besides the inscription. A very beautiful one was drawn and modelled by Mr. Wyon; but there would be the additional expense of one hundred guineas necessary to have this design executed. This could only be effected by asking the subscribers either to pay a portion of the value of their own medals, or to subscribe some additional sum; and it was thought advisable to draw the attention of the subscribers at large by a circular, rather than by the fuss and tumult of a public meeting. If this circular had been more explicit, no mistake could possibly hare arisen; and I think you will be ready to acknowledge that there has been nothing unreasonable in the application. I remain, Sir, your obedient servant,

Dec. 21, 1841 .

\section{RESPIRATOR SOCIETY.}

\section{To the Eiditor of The LANCET.}

$S_{I R},-I$ have often regretted, while prescribing for the poor patients at the London Dispensary, afflicted with asthma and other diseases of the lungs, that they have been unable to furnish themselves with one of Mr. Jeffry's respirators, which would materially assist in relieving their sufferings, although the price of some of them has been reduced, as I am informed, to seven shillings, in order to allow of their being purchased by individuals who are unable to atford the original price.

I need scarcely point out to those who are conversant with the necessities of the poor in this great metropolis, how incompetent numbers of them are to spare seven shillings for disorders of respiration. Would not, then, a 